\title{
Pengenalan Pola Gerak Mulut Dengan Menggunakan Pendekatan SOM (Self Organaizing Feature Map)
}

\author{
I Gede Aris Gunadi \\ Jurusan Pendidikan Fisika, FMIPA \\ Universitas Pendidikan Ganesha Singaraja \\ Singaraja-Bali, Indonesia \\ Aria_sukaat@yahoo.com
}

\author{
Agus Harjoko \\ Lab Elektronika dan Instrumentasi, FMIPA \\ Universitas Gajah Mada \\ Yogyakarta , Indonesia \\ aharjoko@ugm.ac.id
}

\begin{abstract}
Pengenalan pola gerak mulut merupakan salah satu acuan yang digunakan untuk pengenalan ekspresi emosi manusia berdasarkan ekspresi wajah. Emosi manusia dapat diklasifaksikan menjadi enam sampai tujuh katagori yaitu, marah, khawatir, sedih, jijik.bahagia, terkejut, dan normal. Dalam penelitian ini akan dilakukan pengenalan pola gerak mulut yang terjadi dalam sebuah adegan rekaman video.Rekaman video terlebih dahulu diekstraksi dalam bentuk image frame. Pada setiap image frame dilakukan segmentasi untuk mendapat area mulut. Metode segmentasi mulut yang digunakan adalah dengan menggunakan peta mulut, yang didasarkan pada warna bibir yang khas. Proses selanjutnya adalah melakukan crooping berdasarkan tepi mulut yang sudah tersegmentasi. Selanjutnya dilakukan penentukan feature tepi dari hasil crooping yang didapat. Pada Tahap akhir dilakukan pengenalan pola gerak mulut dengan menggunakan metode SOM ( selft Organaizing feature Maps), sehingga pola gerak mulut yang sejenis akan berada dalam cluster yang sama. Hasil eksperiment menunjukan pengenalan gerak mata dengan menggunakan SOM mampu menidentifikasi dengan keakuratan $83 \%$.
\end{abstract}

Keywords : Jaringan Kohenen, SOM, Pengenalan Pola, Segmentasi Mulut.

\section{PENDAHULUAN}

Analisa gerak gerak mulut merupakan bagian yang sangat penting dalam pengenalan ekspresi emosi manusia. Secara umum literatur literatur psikologi membagi emosi manusia tujuh yaitu, anger, disgust, fear, happiness, sadness,surprise, contempt $[1,2]$. Pengenalan pola gerak mulut atau ekspresi oral menjadi sangat penting, berdasarkan formula FACs ( Facial Action Code) pengenalan ketujuh jenis emosi selalu melibatkan AUs (Action Units) otot otot di daerah mulut [3]. Dalam analisa kebohongan yang didasarkan micro gesture wajah, secara dominan melibatkan daerah wajah bagian bawah, yang dominan berada pada area mulut [4].
Mulut adalah salah satu bagian dari ekspresi wajah yang dapat dikaitkan dengan emosi seseorang, pada orang marah ekspresi mulutnya tentu berbeda dengan orang yang berbahagia. Bahkan pada orang yang benar benar bahagia dengan orang yang pura pura bahagia, ekspresi mulutnya akan berbeda. Dalam [5], beberapa ekpresi yang dikaitkan dengan mulut, antara lain: Jaw Droop ( Rahang menurun ) dikaitkan dengan mulut terbuka yang kemungkinan memiliki makna keterkejutan , Lip Compression menyatakan kondisi tertekan atau stress, Lip pout ( menyebil) menyatakan kondisi ketidak puasan.

Dalam bidang computer science beberapa studi dan penelitian yang dikaitkan dengan mulut, pada umumnya dikaitkan dengan masalah deteksi mulut. Diantaranya $[6,7,8]$, penelitian untuk mendeteksi mulut berdasarkan warna bibir. Penelitian dilakukan dalam sistem warna $\mathrm{YCbCr}$, area mulut memiliki karakter kuat pada komponen warna merah dan lemah pada komponen warna biru, dibanding area wajah lainnya. Berdasarkan fakta tersebut dirumuskan sebuah formula untuk mendeteksi mulut yang dikenal dengan Mouth Map. Salah satu penelitian yang dikaitkan dengan pengenalan gerak otot otot pada wajah adalah, penelitian untuk mengukur dan mengidentifikasi mikrogesture dengan menggunakan $3 \mathrm{D}$ gradient descriptor dan kamera yang digunakan memiliki spesifikasi khusus dengan frame rate 200 fps [7]. Kamera kecepatan tinggi diperlukan untuk menangkap micro gesture (gesture yang yang durasi kejadiannya sangat singkat, kurang dari setengah detik).

Jaringan kohenen SOM adalah salah satu model pengembangan jaringan syaraf tiruan yang proses pembelajarannya tidak terbimbing (unsupervised), model ini sangat cocok dipakai untuk pengenalan pola masukan ke dalam beberapa cluster. Pengembangan jaringan kohenen dikenal dengan SOM ( Selft Organaizing Feature Maps) atau kohenen Map. Keluaran jaringan 
adalah cluster dengan anggota anggota yang paling mirip $[9,10]$.

Dalam digunakan pendekatan peta mulut (mouth map) sebagai metode segmentasi mulut dan kohenen SOM untuk mengenali pola gerak mulut pada sebuah adegan video. Metode segmentasi mulut dibahas pada bagian II, pada bagian III akan dibahas tentang metode cropping area mulut, pada bagian IV dibahas tentang fitur mulut yang digunakan, percobaan, pada bagian $\mathrm{V}$ dibahas tentang pengenalan pola dengan SOM dan hasil dibahas pada bagian VI, dan bagian VII tentang kesimpulan.

\section{SEGMENTASI AREA MULUT.}

Bibir memiliki karakter warna yang khas yaitu warna merah kuat sedang warna biru rendah, dibandingkan dengan area lain pada wajah. Berdasarkan fakta tersebut diturunkan formula untuk mendeteksi mulut, yang dikenal dengan mouth map [11]. Rumusan peta mulut dinyatakan dalam persamaan 1 .

$$
\begin{aligned}
& \text { MouthMap }=\mathrm{Cr}^{2} \cdot\left(\mathrm{Cr}^{2}-\eta \cdot \mathrm{Cr} / \mathrm{Cb}\right)^{2} \\
& \eta=0.95 x\left((1 / \mathrm{N}) \Sigma \mathrm{Cr}^{2}\right) /((1 / \mathrm{N}) \Sigma(\mathrm{Cr} / \mathrm{Cb})(2) \\
& \mathrm{N}=\text { ukuran spatial dari image wajah. }
\end{aligned}
$$

Proses yang dilakukan adalah analisa dilakukan pada sistem warna $\mathrm{YCbCr}$, pada umumnya sistem warna yang digunakan adalah RGB, sehingga dilakukan konversi dari RGB ke YCbCr. Hubungan system warna RGB dengan $\mathrm{YCbCr}$ adalah :

$$
\left[\begin{array}{c}
Y \\
C b \\
C r
\end{array}\right]=\left[\begin{array}{c}
16 \\
128 \\
128
\end{array}\right]+\left[\begin{array}{ccc}
65.481 & 128.553 & 24.966 \\
-37.797 & -74.203 & 112 \\
112 & -93.786 & -18.214
\end{array}\right]+\left[\begin{array}{l}
R \\
G \\
B
\end{array}\right]
$$

Proses normalisasi dilakukan pada komponen $\mathrm{Cr}^{2}$ dan $\mathrm{Cr} / \mathrm{Cb}$, sehingga nilai komponen warna tetap berkisar antara $0-255$. Gambar 1 menunjukan image dalam komponen $\mathrm{RGB}, \mathrm{Cr}^{2}, \mathrm{Cr} / \mathrm{Cb}$, dan $\mathrm{Cb} / \mathrm{Cr}$.

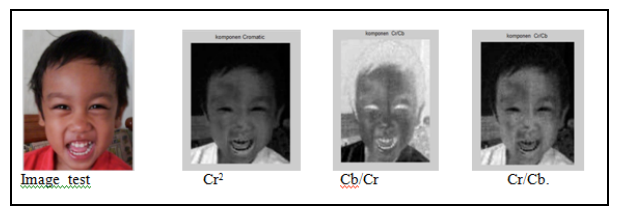

Gambar. 1. Image dalam komponen $\mathrm{YCbCr}$

Komponen $\mathrm{Cr}^{2}$ dan $\mathrm{Cb} / \mathrm{Cr}$ digunakan dalam (1), untuk mendeteksi letak mulut. Hasil deteksi sangat dipengaruhi data inputannya, kemungkinan adanya noise akan sangat mempengaruhi hasil segmentasi mulut. Gambar 2 menunjukan hasil uji coba deteksi mulut dengan (1).

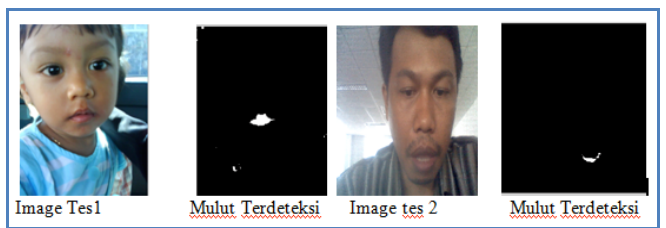

Gambar .2. Segmentasi mulut dengan peta mulut

Pre processing sangat diperlukan untuk menghilangkan adanya noise, yang diakibatkan proses capture video yang masih kurang sempurna. Dalam penelitian ini ditemukan noise pada hasil segmentasi dengan peta mulut, ditunjukan dalam Gambar 3.

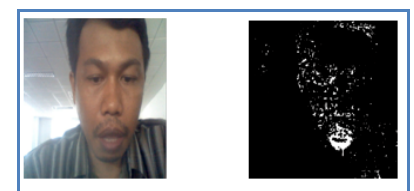

Gambar 3. Noise pada hasil segmentasi mulut .

Dalam percobaan ini dicoba untuk memisahkan antara noise dengan area mulut dengan proses morfologi dilatasi dengan ukuran kernel $(7,7)$. Ukuran kernel $(7,7)$ merupakan hasil uji coba yang paling ideal, titik noise bisa tereduksi namun titik putih area mulut masih dominan. Hasil proses morfologi secara umum noise cukup tereduksi, namun tetap masih ada. Proses kompresi dilakukan dengan mengecilkan ukuran image frame, dan hasilnya secara signifikan dapat mengurangi noise. Hasil yang ideal didapatkan pada ukuran 250 x 250, pada kondisi ini noise sudah bisa dihilangkan. Tabel I menunjukan hasil ujicoba perubahan ukuran image frame dan pengaruh noise.

TABEL I . UKURAN KOMPRESI IMAGE DAN PENGURANGAN NOISE

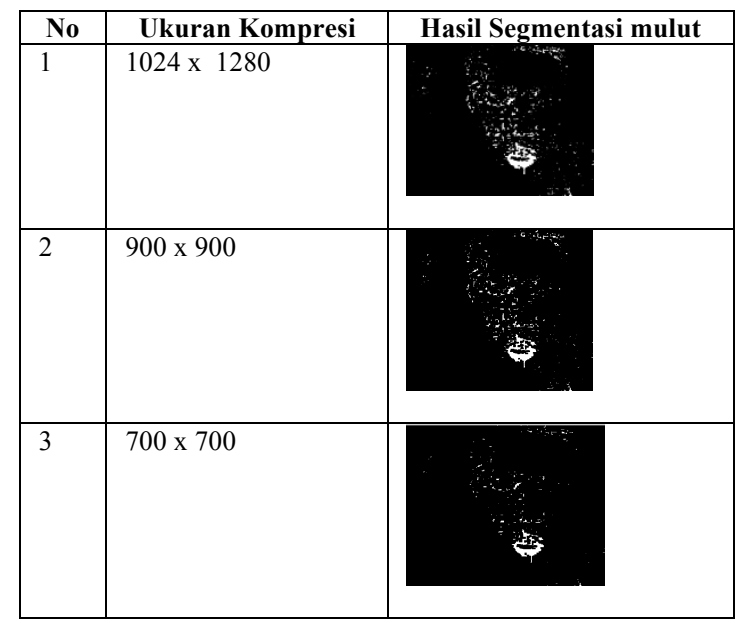




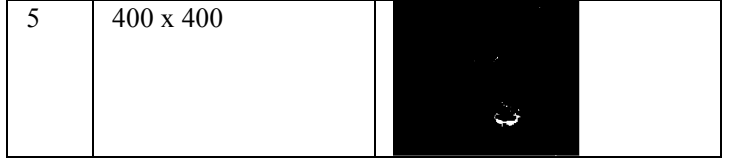

\section{CROPPING AREA MULUT.}

Dari hasil deteksi mulut yang telah dilakukan, kemudian dilakukan deteksi tepi mulut dengan tujuan untuk mendapatkan tepi tepi mulut, tepi atas bawah, tepi kiri kanan. Titik titik tersebut dijadikan acuan untuk melakukan cropping area mulut ,ditunjukan Gambar 4. Proses tersebut berikut hasil cropping ditunjukan Gambar 5.

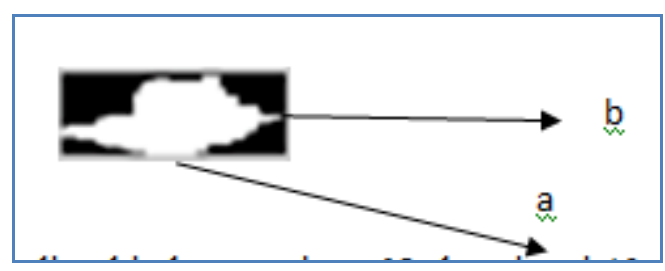

Gambar .4. Titik acuan untuk cropping mulut

Titik a dan b akan dijadikan acuan untuk cropping mulut pada setiap frame.

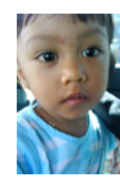

Image Test

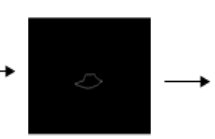

Tepi mulut yang terdeteks

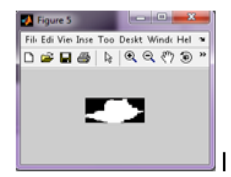

Bagian Mulut yang di croping
Gambar .5. Proses crooping mulut dan hasil cropping .

Hasil cropping area mulut pada setiap frame video akan berbeda beda tergantung pada titik acuannya, sehingga ukuran (size) citra akan berbeda beda mulut. Sehingga untuk proses perhitungan perlu dilakukan normalisasi, penyamaan ukuran citra. Pada penelitian ini setelah dinormalisasi ukuran hasil cropping pada setiap frame video adalah 41 x 66 pixels.

\section{FITUR MULUT.}

Kontur tepi sering digunakan untuk mengidentifikasi sebuah image, misalnya dalam mengenali sidik jari. Sama seperti jari area mulut juga memiliki guratan guratan tertentu, setiap gerak mulut tertentu akan memiliki bentuk guratan atau kontur tepi tersendiri. Pada beberapa beberapa gerak mulut yang telah disegmentasi dilakukan deteksi tepi dengan operator canny, didapatkan hasil bahwa untuk setiap gerak mulut tertentu memiliki pola guratan tepi tertentu. Tabel I menunjukan berbagai pola gerak mulut dan guratan tepinya.
TABEL II. POLA GERAK MULUT DAN BENTUK GURATAN TEPI

\begin{tabular}{|l|l|l|l|}
\hline No & $\begin{array}{c}\text { Image pola } \\
\text { gerak mulut }\end{array}$ & Deteksi tepi & \\
\hline 1 & & & \\
\hline 2 & & & \\
\hline 4 & & & \\
\hline 5 & & & \\
\hline
\end{tabular}

\section{PENGENALAN POLA DENGAN SOM}

SOM (selft Organizing Map) adalah sebuah metode pengenalan pola yang tidak terbimbing. Tujuan dari metode ini adalah membentuk cluster sesuai dengan kedekatan ciri atau features dari masing masing item. Ciri yang digunakan dalam penelitian ini adalah bentuk guratan tepi, masing masing state gerak mulut memiliki bentuk guratan tepi tertentu (ditunjukan dalam Tabel II).

Pengenalan pola dengan SOM, terdiri atas dua fase yaitu fase training dan fase pencocokan dijelaskan sebagai berikut

\section{A. Fase training}

1. Untuk setiap image hasil crooping area mulut yang berukuran $\mathrm{j}$ x k , dijadikan sebuah flat vector $1 \mathrm{x} \mathrm{m}$, dimana $\mathrm{m}=\mathrm{j} \mathrm{xk}$. Dalam penelitian ini ukuran(size) adalah 41 x66 pixels.

2. Mula mula inisialisasi bobot $\mathrm{W}$, dibangkitkan secara acak dengan nilai elemen matrik antara 0 - 255 dan ukurannya adalah $\mathrm{n} \times \mathrm{m}$, dimana $\mathrm{n}$ adalah jumlah cluster yang diinginkan dan $\mathrm{m}$ adalah ukuran flat vector citra.

3. Dilakukan $q$ kali iterasi ( $q$ adalah jumlah citra inputan yang diuji untuk pembentukan cluster), dalam setiap iterasi dilakukan pengecekan/ perhitungan untuk setiap vector inputan citra (vector inputan adalah flat vector citra, pada langkah 1), temukan jarak yang paling minimum antara vector inputan dengan dengan setiap baris dari matrik bobot W ( ilustrasi dalam Gambar 6 ) 


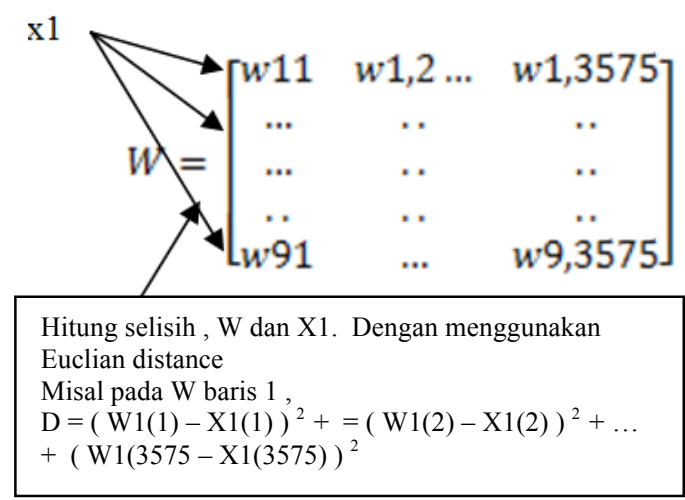

Gambar. 6. Penghitungan Bobot Untuk Setiap Inputan

4. Dari langkah 2, didapatkan 9 jarak, tentukan yang paling minimum pada baris ke berapa. Pada baris dengan jarak minimum lakukan modifikasi Bobot $\mathrm{W}$, dengan aturan

$$
\mathrm{W}_{(\mathrm{I}, \mathrm{j})}^{\text {baru }}=\mathrm{W}_{\text {lama (I.j) }}+\alpha(0)\left(\mathrm{Xi}-\mathrm{W}_{\text {lama (I.,j) }}\right)
$$

5. Lakukan langkah 2,3 sampai vector inputan X9 (semua vector sudah melakukan modifikasi bobot).

6. Setelah langkah 2,3,4 dan 5 dilakukan berarti satu iterasi selesai, lakukan iterasi berikutnya dengan langkah yang sama seperti 2,3,4. Dengan menyesuaikan perubahan laju pemahaman ,

$$
0.5 \alpha(\mathrm{t})=\alpha(\mathrm{t}+1)
$$

Iterasi dianggap cukup, bila perubahan matrik bobot sangat kecil, sudah dianggap konvergen.

\section{B. Fase Pencocokan}

Pencocokan dapat dilakukan, setelah didapat bobot yang ideal. Citra inputan (dalam bentuk flat vector) diuji , mencari jarak mana yang paling minimum pada Matrik bobot idealnya. Misal minimum pada baris 2 , berarti polanya sesuai dengan pola pada baris no 2 .

\section{HASIL PERCOBAAN DAN ANALISA}

Pada tahap awal dilakukan perekaman video dan ekstraksi image frame. Proses pengambilan video menggunakan web camera, Lenovo Easy Camera, ( Device ini merupakan bawaan pada Lenovo, diproduksi Vimicro ), dengan resolusi maksimal $1280 \times 1024$. Jenis video yang digunakan berupa *. Wmv. Proses ekstraksi rekaman video menjadi image frame penyusunnya, menggunakan softwere Forevid( open source).Objek yang diambil dalam rekaman video adalah tubuh bagian atas, bagian muka. Gambar 7 menunjukan tampilan interface dari foreVid

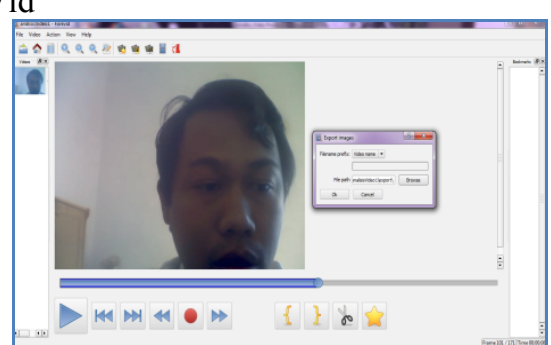

Gambar . 7. Tampilan Interface Forevid Rekaman video tersebut selanjutnya diekstraksi menjadi image frame, proses ekstraksi dari video menjadi image frame menggunakan fitur fitur yang sudah tersedia pada forevid. Gambar 8 menunjukan hasil image frame yang telah di ekstraksi.

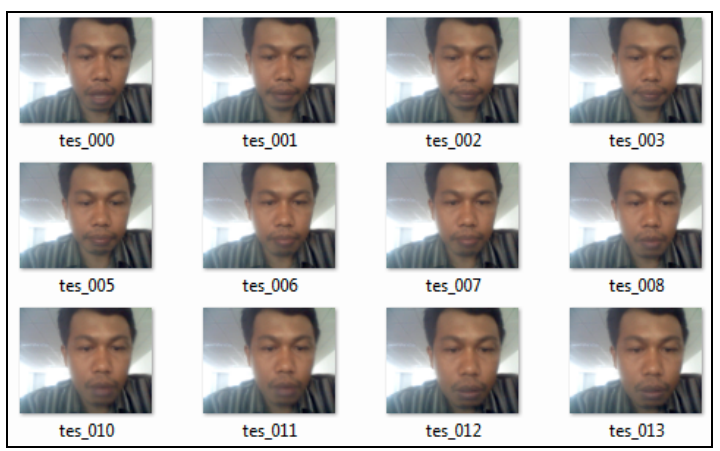

Gambar .8 . Image frame hasil ekstraksi dari rekaman video

Proses pungujian pengenalan pola gerak mulut dilakukan pada sejumlah sampel ( 75 image frame). Fitur mulut dalam bentuk guratan guratan tepi mulut diekstrasi dengan ukuran $66 \times 41$ pixel, kemudian dilakukan proses pengelompokan dengan mengunakan SOM atau kohenen map. Proses validasi dilakukan dengan membandingkan pengamatan dan penilaian secara visual, dalam sebuah cluster dibandingkan apabila terdapat image yang berbeda dengan image yang dominan dalam cluster tersebut, maka image tersebut dianggap salah dan sebaliknya dikatakan benar. Gambar 9,10,11,12,13 dan 14 menunjukan hasil pengujiancluster, indek tn/ status, menunjukan nomberimage frame yang diuji dan statusnya( $\mathrm{S}$ : Salah,B: Benar) misal t10/S : image frame 10 , status Salah. Dari hasil pengujian 75 image frame didapatkan 6 cluster. 


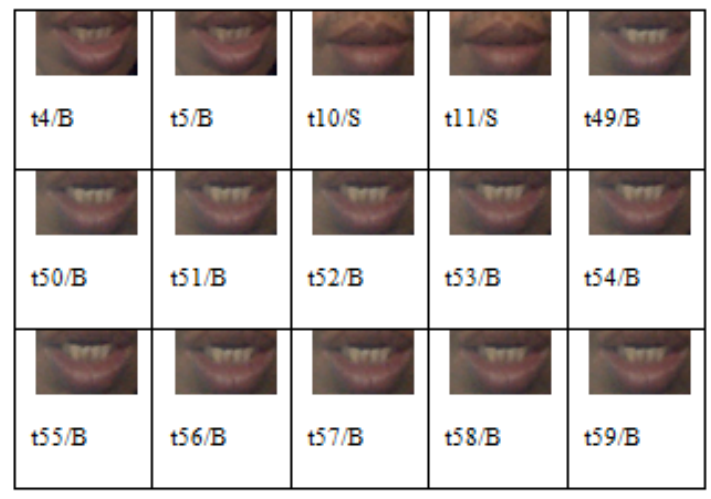

Gambar. 9. Hasil Pengujian Cluster 1

Karakteristik cluster 1 : Mulut Terbuka penuh ,Bagian Gigi Kelihatan Secara Jelas. Anggota cluster : 15 , Tidak sesuai secara visual 2 buah yaitu frame 10 dan 11 .

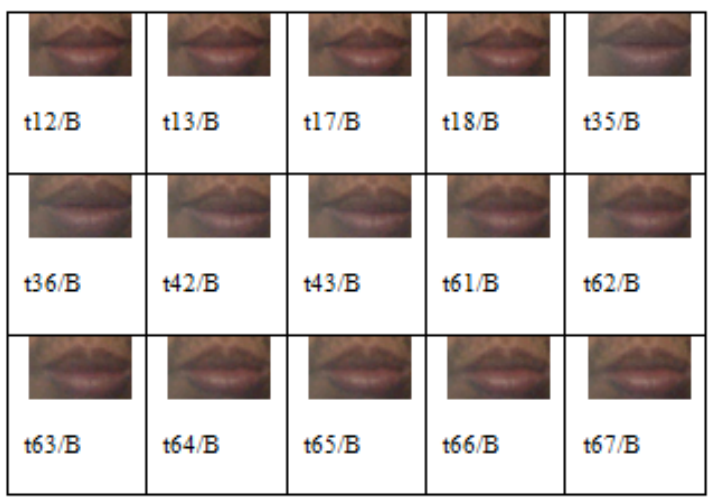

Gambar. 10. Hasil Pengujian Cluster 2

Karakteristik cluster 2 adalahmulut tertutup normal , Anggota cluster 15, secara visual semua anggota cluster validasinya benar.

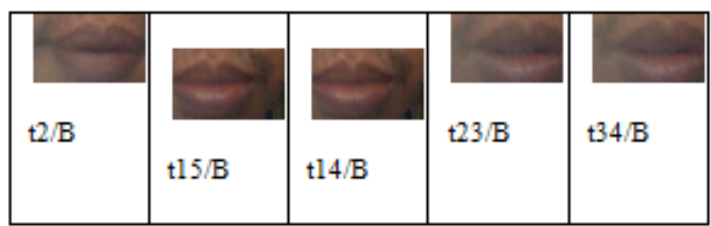

Gambar. 11. Hasil Pengujian Cluster 3

Karakteristikcluster 2 menunjukan mulut tertutup Normal, anggota cluster 5, validasi semua anggota cluster benar.

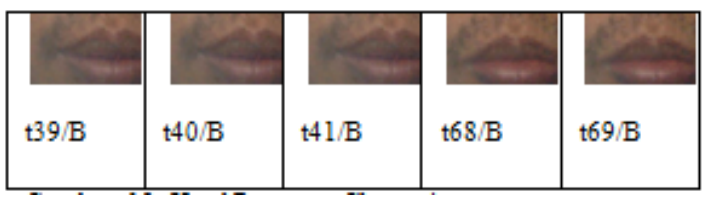

Gambar. 12. Hasil Pengujian Cluster 4

Kararakteristik cluster 4 adalah mulut tertutup normal, secara visual semua anggota cluster validasinya benar.

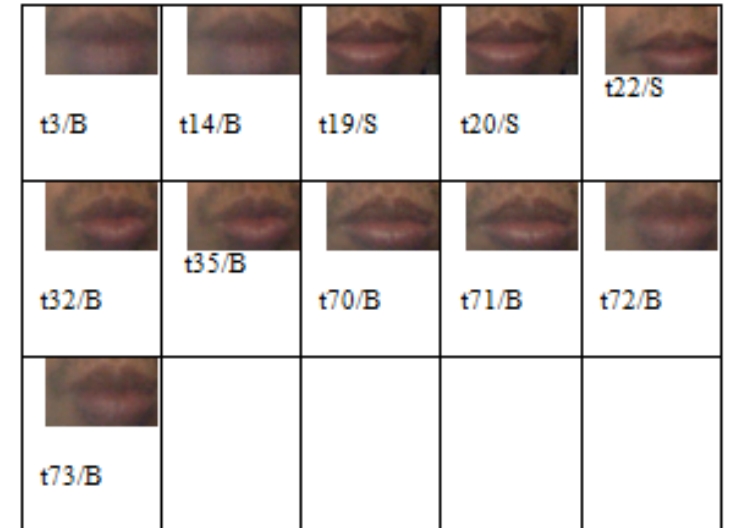

Gambar. 13. Hasil Pengujian Cluster 5

Karakteristik cluster 5 adalah mulut dengan bibir atas tertarik kedalam dan bibir bawah keluar (nyebil) anggota cluster 11 . Validasi ditemukan 3 image frame yang tidak sesuai, yaitu frame 19,20,22 . image frame tersebut lebih sesuai dengan mulut yang tertutup normal.

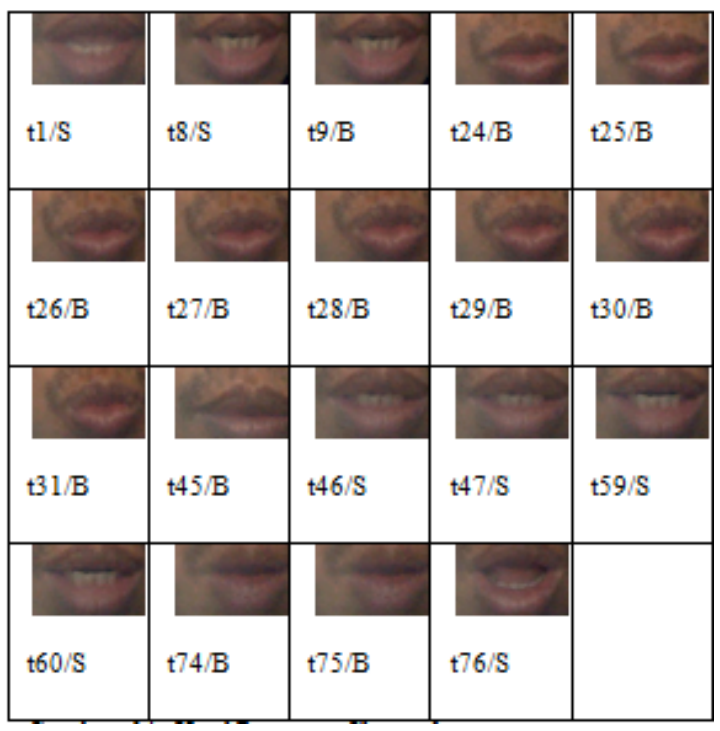

Gambar. 14. Hasil Pengujian Cluster 6

Karakteristik cluster 6 adalah mulut cendrung maju, anggota cluster : 19 , validasi salah :7 pada frame $1,8,46,47,59,60,76$

Dari 75 data image frame yang diambil didapatkan 13 frame yang tidak tepat letak klusternya.

Presentase kesalahan : $13 / 75 * 100 \%=17 \%$

Presentase kebenaran :83 \%

Berdasarkan hasil pengujian sebenarnya, cluster 2,3,4 sebenarnya menunjukan bentuk gesture mulut yang sama, mulut tertutup normal. Penyebab terjadinya cluster yang berbeda adalah karena potongan crooping yang berbeda, cluster 2 
hasil area mulut yang dicropping menunjukan hasil yang ideal, sedang pada cluster 3 ada daerah samping mulut yang terpotong lebih ( hasil cropping cendrung ke kanan), dan pada cluster 4 area samping kiri cendrung lebih. Hal ini diakibatkan hasil deteksi tepi mulut yang tidak maksimal. Disekitar mulut terdapat titik titik noise yang terdeteksi sebagai tepi mulut, dan titik titik tersebut dijadikan acuan melakukan cropping. Sehingga hasil cropping pada beberapa image frame menjadi kurang maksimal.Permasalahan noise dalam deteksi tepi adalah menmunculkan tepi salah, yaitu noise yang dikenali sebagai tepi [12]. Hasil visualiasi pola gerak bibir untuk tiap image frame ditunjukan dalam grafik gambar 15.

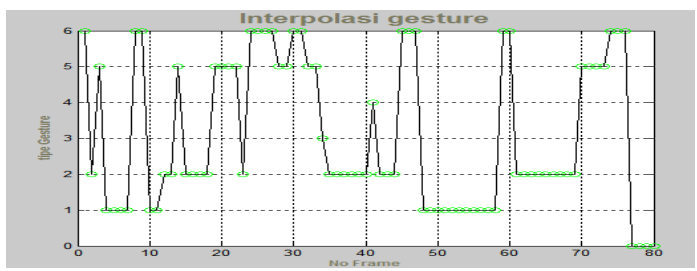

Gambar 15. Visualisasi Gerak Bibir tiap Image Frame, Tipe Gesture 1: terbuka penuh, 2: normal ( 3,4 : normal, dalam visualisasi grafik dinyatakan dengan 2), 5 : nyebil , 6 : Mulut mulut dari setengah terbuka, sampai cendrung maju.

\section{SIMPULAN}

Dari penelitian yang telah dilakukan dapat disimpulkan beberapa hal, pertama penggunaan SOM untuk pengenalan gerak mulut sangat ditentukan oleh keakuratan hasil segmentasinya. Seperti dalam percobaan ini karena ada pengaruh noise yang tersisa dalam segmentasi citra, akan mengakibatkan kesalahan pada proses pengklusteran oleh SOM. Noise tersebut menyebabkan timbulnya tepi salah, yaitu noise yang terdeteksi sebagai tepi. Hal ini akan mempengaruhi fitur guratan tepi yang dihasilkan, sehingga mempengaruhi hasil cluster. Secara umum pengenalan pola gesture (pola gerak/ mimik mulut) dengan menggunakan SOM dapat dikatakan berhasil, dari 75 sampel image frame yang diuji presentase keakuratannya berkisar $83 \%$

Kedua kelemahan SOM dalam pengenalan pola adalah kurang adaftif terhadap perubahan jumlahan sampel. Pada saat penambahan sejumlah sampel data baru maka SOM melakukan perhitungan dari awal kembali, seolah olah ini adalah ini adalah data baru. Sehingga secara komputasi kurang baik.

Ketiga berkaitan dengan proses pengenalan polanya, fitur pola guratan tepi pada area mulut dapat dijadikan salah satu alternatif untuk mengenali pola gerak/ mimik mulut. Pada prinsipnya fitur ini adalah fitur tepi, fitur ini cukup sederhana dan mudah proses ekstraksinya maupun dalam komputasi pengenalan pola dibanding dengan fitur panjang/ lebar dan tinggi mulut (fitur geometri mulut).

\section{UCAPAN TERIMA KASIH}

Terima kasih yang sebesarnya penulis sampaikan kepada semua pihak yang telah membantu penulisan jurnal ini, terutama kepada seluruh staf pengajar di program doktoral ilmu computer UGM, staf administrasi ELINS UGM, rekan rekan di FMIPA UNDIKSHA Singaraja Bali dan kepada teman teman di program S3 ilmu computer UGM yang selalu saling memberi semangat.

\section{DAFTAR PUSTAKA}

[1] Gunadi Aris IG, Harjoko Agus, "Telaah Metode metode Pendeteksi kebohongan ", Indonesian Journal of Computing And Cybernetic Sistems, Vol 6.No 2, pp 35 46, 2012.

[2] L Catherine, Harris Caldwell, Ayase Aycicegi D, "Emotion and Lying in Non Native Language", International Journal of Psychophysiology Vol 71, pp 193 -204, September 2008.

[3] Matsumoto D, Hwang H S, Skinner L, Frangk M G, "Evaluating Truthfulness and Detecting Deception" FBI Law Enforcement Bulletin, vol 80, pp 1-25, 2011

[4] Stephen Porter,Leanne Ten Brinke, 2008, "Reading Between The Lies: Identifying Concealed and Falsified in Universal Facial Expressions", Journal of Psychological Science,Vol 19 No 5, pp 508-514, 2008.

[5] Navaro Joe, Karlin Marvin, What Every Body is Saying, Harver Collin Publishe, Pymble Australia , 2008.

[6] Oravec Milos, Kristof Branislav,Kolarik Michal, Pavlovicova J, "Extraction of Facial Features from Color Images”, RadioEngineering, Vol 17, Hal 115 -120 , 2008.

[7] Adipranata Rudy, G Cherry, Ongkodjojo Ronald P , “ Fast Method for Multiple Human Face Segmentation in Color Image",Second International Conference on Future Generation Communication and Networking, 2008

[8] .R Agustina Dewi, Karmilasari, Tanjung Fahmi, “ Extraction Application of Face Feature/ Component “, $2^{\text {nd }}$ Information and Communication Tecnology Seminar ,2006.

[9] Jong Sek Siang, Jaringan Syaraf Tiruan dan Pemorogramnya Menggunakan Matlab , EdisiI, Andy Offset, Yogyakarta, 2005

[10] Vesanto Juha, Johan Himberg, Alhoniemi Esa, Juha Parhankangas, "Selft Organizing Map in Matlab : The SOM Toolbox ", Procedings of The Matlab DSP Confrence, Filandia, pp 35 -40, November 1999.

[11] Christopher B, Boehnen,B.S A Multi-Modal Approach to Frontal and Non Frontal Facial Feature, University of Notre Dame in Computer Science and Engineering Indiana, 2005.

[12] Gunadi Aris IG, Wardoyo Retantyo, “ Ekstraksi Tepi dengan Menggunakan Fuzzy Spatial Filtering dan Slicing Intensity “, Seminar Nasional Teknologi Informasi dan Aplikasinya, Denpasar Bali, pp 14-22, Oktober 2012. 